Vol. 11 (2): 245-250 (2021)

\title{
FLOOD HAZARD OF BONGABON, NUEVA ECIJA, PHILIPPINES: A VULNERABILITY AND RISK ASSESSMENT
}

\author{
Eros A. Castillo ${ }^{1}$, Mario M. Abesamis, Jr. ${ }^{1}$, Michael Angelo S. Rivera ${ }^{1}$, \\ John Rey B. Quiñones ${ }^{1 *}$, Noel B. Coloma ${ }^{1}$ \\ ${ }^{1 *}$ College of Arts and Sciences, Nueva Ecija University of Science and Technology, \\ Cabanatuan City, Philippines, 3100;
}

*Corresponding Author John Rey B. Quiñones, e-mail: johnrey201334@gmail.com;

Received January 2021; Accepted February 2021; Published March 2021;

DOI: https://doi.org/10.31407/ijees11.207

\begin{abstract}
This study was conducted to assess the vulnerability and risk of selected barangays of Bongabon, Nueva Ecija in terms of exposure, sensitivity and adaptive capacity. It assessed the total number of people exposed to flood hazards, the sensitivity or threat level and the adaptive capacity of each barangay to withstand the flood hazard. This study used descriptive analytical method to analyze the degree of high-risk barangays of Bongabon, Nueva Ecija based on its present condition. The data gathering procedure was done through survey form which contains the items that describe exposure, sensitivity, and adaptive capacity. The scoring based on the LCCAP Guidelines was used to determine the exposure and vulnerability of high-risk barangays of Bongabon. Data showed that Barangay Lusok was the most exposed barangay to flood hazard due to the number of affected families in times of flooding. In threat level category, all of six barangays were categorized to moderate sensitivity. In adaptive capacity, majority of the barangays were classified as Medium Low while in relative vulnerability, majority of barangays were classified as Medium to Nearly Medium. In estimation of risk category, the six selected barangays were classified as High. Findings of this study served as an encouragement for the creation and formulation of the updated Local Climate Change Action Plan (LCCAP) for the municipality in order to improve its present adaptive capacity and to mitigate the serious effects of hazards in both human and environment.
\end{abstract}

Keywords: flood hazard, risk assessment, environment, municipality. 